\title{
Synthesis and characterization of silver nanoparticles embedded in polyaniline nanocomposite
}

\author{
Y. B. Wankhede ${ }^{1}$, S. B. Kondawar, ${ }^{2,}$, S. R. Thakare ${ }^{3}$, P. S. More ${ }^{4}$ \\ ${ }^{I}$ Rajiv Gandhi College of Engineering, Research and Technology, Chandrapur, India \\ ${ }^{2}$ Department of Physics, RTM Nagpur University, Nagpur, India \\ ${ }^{3}$ Centre for Nanotechnology, Shivaji Science College, Nagpur, India \\ ${ }^{4}$ Department of Physics, Vidarbh Institute of Science and Humanities, Amaravati, India
}

*Corresponding author. E-mail: sbkondawar@yahoo.co.in

\section{ABSTRACT}

Conducting polyaniline/silver nanoparticles (PANI-Ag) nanocomposite was synthesized by in-situ polymerization of aniline in the presence of silver nitrate as precursor. Nanocomposite was characterized by UV-VIS, PL, XRD, FTIR, SEM and TGA to study the effect of silver nanoparticles embedded into PANI on the morphology, structure, crystalline and thermal stability of the conducting polyaniline. The optical studies show that the absorption edge of PANI-Ag nanocomposite exhibits the significant blue shift. The photoluminescence studies show that the emission peak shifted towards the blue when compared to that of bulk PANI-Ag. The broadening sharp peaks in the XRD pattern indicate that the synthesized PANI-Ag nanocomposite is nanocrystalline. FTIR reveals the presence of silver metal ions uniformly embedded into PANI. SEM reveals the rod structure surface morphology of PANI-Ag nanocomposite. Thermogravimetric analysis suggests the presence of silver and also an oligomeric component in the nanocomposite. The combination of PANI as a semiconducting polymer with silver as a noble metal may produce hybrid material that behaves as semiconductor at low temperature and as metal at high temperature. Copyright (C) 2013 VBRI Press.

Keywords: Silver nanoparticles; conducting polymers; polyaniline; nanocomposites.

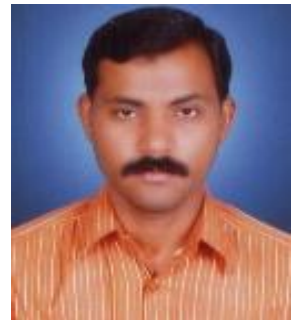

Y. B. Wankhede is an Assistant professor of Applied Physics at Rajiv Gandhi College of Engineering, Research and Technology, Chandrapur, Maharashtra, India. He did M.Sc. (Physics) from Institute of Science, Nagpur in 2003 and M. Phil. (Physics) from Madurai Kamaraj University, Tamilnadu, India in 2008. He has received Post Graduate Diploma in Nanotechnology from ShriShivaji College of Science, Nagpur in 2011. His research of interests includes synthesis and characterization of conducting polymers, nanocomposites, dielectrics and renewable energy sources. He is doing Ph.D. under the guidance of S. B. Kondawar.

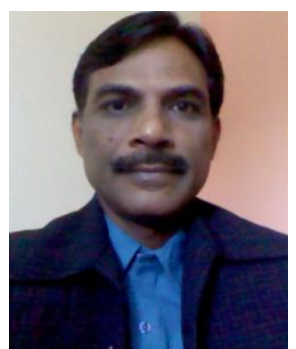

S. B. Kondawar is an Associate Professor of Physics at RashtrasantTukadojiMaharaj, Nagpur University, Nagpur, India. He did Ph.D. from Department of Physics, Institute of Science, Nagpur, India. His main research activities include the synthesis of advanced materials at nanoscale and use them to improve the properties of conducting polymer nanocomposites. His current research is focused on synthesis of conducting polymer nanotubes, nanofibers and nanocomposites for gas sensors, biosensors and solar cells. He has published more than 30 research articles in journals of international repute. He has completed two
UGC, New Delhi (India) funded major research projects and one is ongoing to his credits.

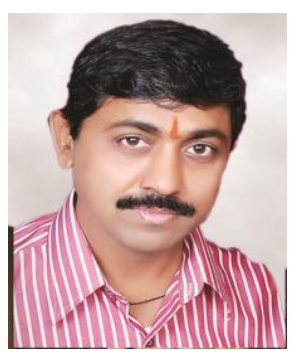

S. R. Thakare is working as Assistant Professor in the Department of Chemistry, Shivaji Science College, Nagpur, India. He did Ph.D. in Chemistry from the RTM Nagpur University, Nagpur, India. He was awarded Junior Research Fellowship by DRDO, India. His current research interests are focused on the synthesis of nanomaterials, photocatalytic degradation of organic pollutants from water bodies, synthesis of conducting polymers and exploring their biological and electronic applications. He has published more than 15 research articles in journals of international repute. 


\section{Introduction}

The nanocomposites with an organized structure usually provide a new functional hybrid, with synergistic properties over their single component counterparts, which have attracted considerable attention for their potential applications [1]. Conducting polymer nanocomposites possess the advantages of both low dimensional systems (nanostructure filler) and organic conductors (conducting polymer). The reinforcement of polymers is done by fillers, which play a major role in strengthening the properties of the nanocomposites. Uniform dispersion of the nanosized filler particles produces ultra large interfacial area per volume between the filler and the host polymer [2]. The conducting polyaniline (PANI) is one of the promising conducting polymers due to its high conductivity, ease preparation, good environmental stability and large variety of applications which make this polymer suitable as a matrix for preparation of conducting polymer nanocomposites[3-4]. It is easily prepared by the oxidation of aniline in aqueous medium. The composites based on conducting polymers and noble metals, such as silver, can be prepared by many ways. Some of the ways are simple blending of both components $[\mathbf{5 , 6 ]}$, the polymerization of aniline in the presence of preformed metal nanoparticles [8], the deposition of metal on conducting polymer while using various oxidants, such as glucose $[8,9]$, the reduction of noble-metal compounds with PANI [10-12] and the oxidation of aniline with noble-metal compounds [13-15]. From the point of view of PANI nanostructures, last approach is the most interesting. Aniline can be oxidized with noble-metal compounds to produce PANI and corresponding metal at the same time. We present here the preparation of conducting polyaniline/silver nanoparticles (PANI-Ag) nanocomposite by in-situ polymerization of aniline in the presence of silver nitrate as precursor using nitric acid and its characterizations.

\section{Experimental}

\section{Materials and methods}

Aniline (99.5\%), silver nitrate $(99.5 \%)$ and ammonium persulphate $(99.5 \%)$ were procured from E. Merck. Aniline was distilled prior to use. All supplementary chemicals were of analytical grade and solutions were prepared with double distilled water. FTIR characterization was done using a Shimadzu FTIR-8101A spectrophotometer via making pellet with $\mathrm{KBr}$ at 8 ton pressure. The XRD measurement was performed on a Philips PW1710 automatic X-ray diffractometer using $\mathrm{Cu}-\mathrm{K} \alpha$ wavelength $(\lambda=1.54059 \AA)$. UV-visible study was carried out on a UV1800 Shimadzu double beam spectrophotometer. Photoluminescence study was carried out on a PC5301 Spectrofluorophotometer. SEM images were taken on JEOL JSM-6360 analytical scanning electron microscopes.

\section{Synthesis of PANI-Ag nanocomposite}

$0.2 \mathrm{M}$ aniline was dissolved in $1 \mathrm{M}$ nitric acid and the $0.5 \mathrm{M}$ silver nitrate was mixed. The solution was oxidised using APS with the same molar ratio to that of aniline and the mixture was kept at room temperature $\left(30^{\circ} \mathrm{C}\right)$. The reaction was slow, characterized by an induction period extending for week. Green solid produced in the oxidation was collected by filter after 2 weeks, rinsed with corresponding nitric acid and dried at room temperature. The reaction is shown in Scheme 1.

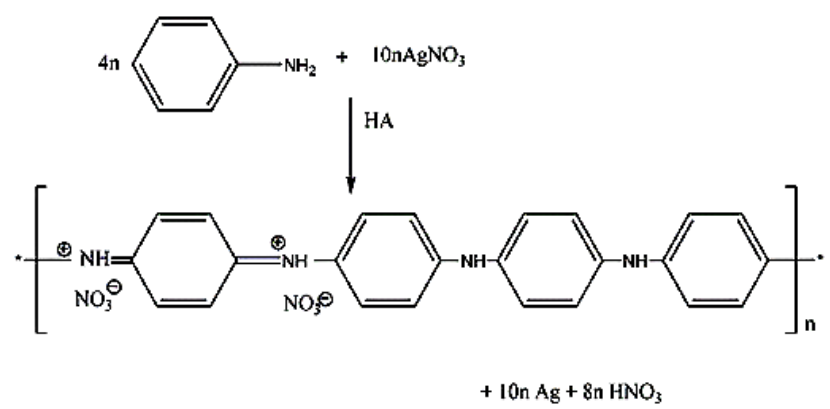

Scheme 1. Aniline is oxidized with silver nitrate to produce PANI nitrate and metallic silver metal.

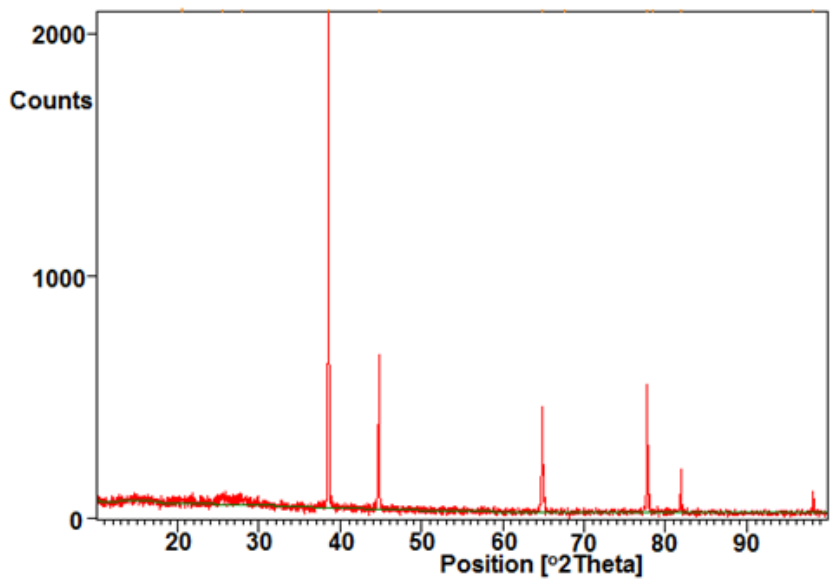

Fig. 1. XRD pattern of PANI-Ag nanocomposite.

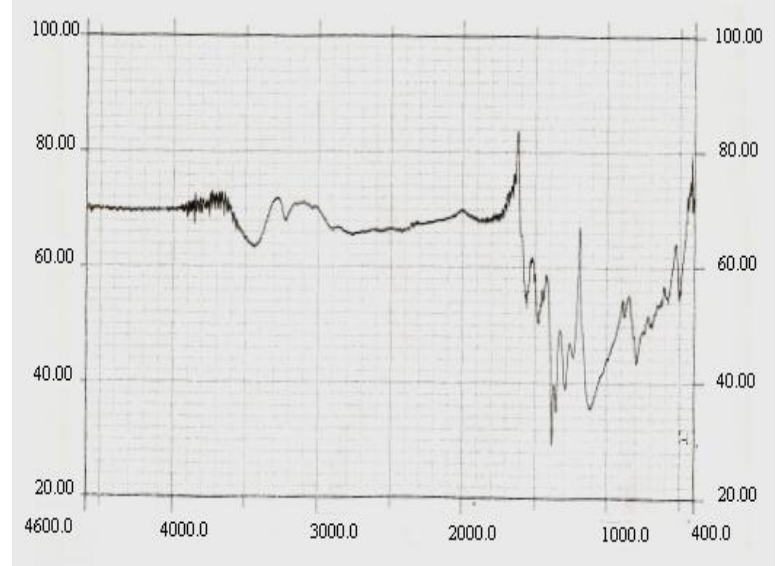

Fig. 2. FT-IR spectra of PANI/Ag nanocomposite.

\section{Results and discussion}

XRD pattern of PANI-Ag nanocomposites is shown in Fig. 1. The sharp peaks of the XRD pattern indicate that the synthesized nanocomposite is well crystalline and confirms the formation of single crystalline $\mathrm{Ag}$ nanoparticles in 
PANI/Ag. Bragg's reflections at $2 \theta=38.2,44.3,64.5$, and 77.4 degree corresponds to $\{111\},\{200\},\{220\}$, and \{311\} lattice planes, respectively, for the face-centered cubic (fcc) structure of silver nanoparticles embedded in PANI. The broadening of peaks shows the formation of nanocomposite and the average crystallite size was estimated to be $12 \mathrm{~nm}$ using Scherrer formula.

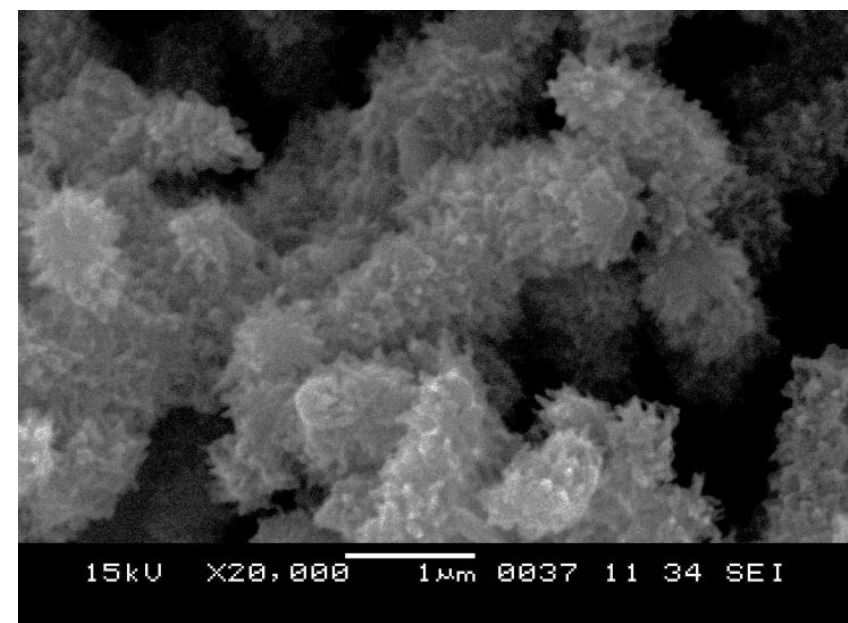

Fig. 3. SEM image of PANI/Ag nanocomposite.

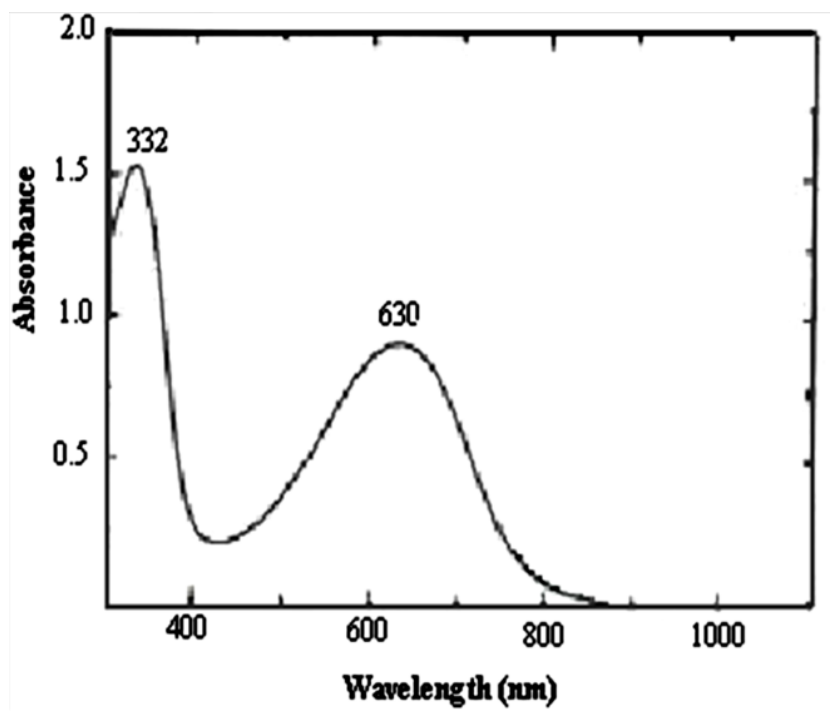

Fig. 4. UV-VIS spectrum of PANI-Ag nanocomposite.

FTIR spectra of PANI-Ag nanocomposite is shown in Fig. 2. The bands related to N-H stretching of an aromatic amine (N-H stretching) normally appear in the region $3223.40 \mathrm{~cm}^{-1}$. The band could be assigned to the asymmetric and symmetric stretching modes of $-\mathrm{NH}_{2}$ group, respectively. The bands corresponding to quinoid $(\mathrm{N}=\mathrm{Q}=\mathrm{N})$ and benzenoid (N-B-N) ring stretching modes were observed at 1560.6 and $1508.5 \mathrm{~cm}^{-1}$ respectively. Another characteristic band in the infrared spectra refers to quinoic unit at about $1240.4 \mathrm{~cm}^{-1}$ arises due to protonation of PANI [16]. The evidence of formation of polyaniline with 1,4-substituted phenyl rings occurred at around 879.6 $\mathrm{cm}^{-1}$. The additional bands at 441.8 and $422.5 \mathrm{~cm}^{-1}$ belonging are due to Ag. The spectra of PANI obtained with silver nitrate as an oxidant in nitric acid resembles the product of aniline oxidation using APS. This product is composed of non-conducting aniline oligomers containing phenazine like units and conducting PANI. Scanning electron microscopy images of PANI-Ag nanocomposite are shown in Fig. 3. It can be seen from the figure that the fine structure of PANI-Ag nanocomposite is slightly agglomerated and form mostly rod like structures.

UV-visible spectrum of PANI-Ag nanocomposite is shown in Fig. 4. It reveals that PANI-Ag nanocomposite is typical of emeraldine state with absorption maxima at 332 and $630 \mathrm{~nm}$. The presence of oligomers is identified by the increased absorption at the $332 \mathrm{~nm}$ with respect to $630 \mathrm{~nm}$. Nanocomposite is optically stable in visible range and can be used in optical devices which have linearity in visible range. The blue-shift is attributed to the quantum confinement of charge carriers in the nanocrystals. The optical studies show that the absorption edge of PANI-Ag nanocomposite exhibits the significant blue shift.

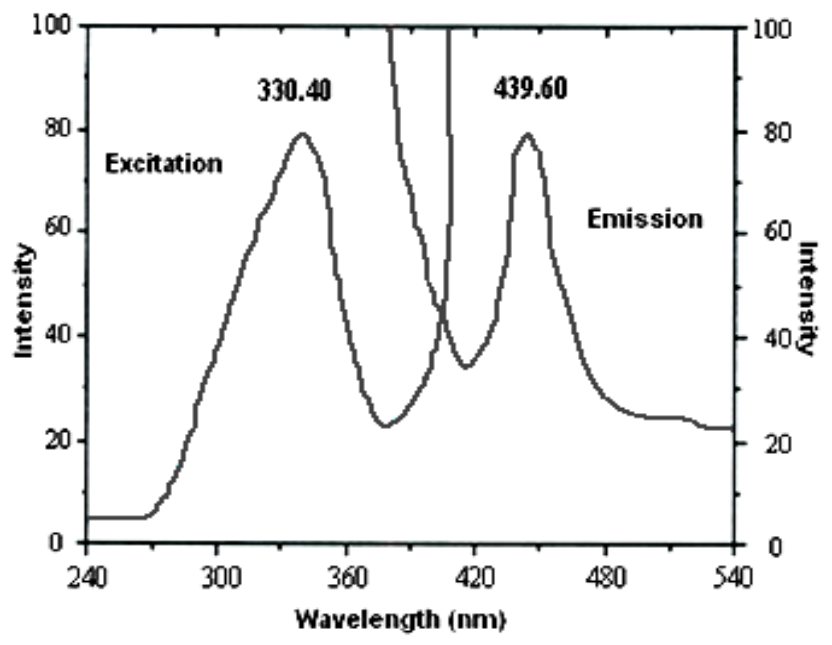

Fig. 5. PL spectrum of PANI-Ag nanocomposites.

The photoluminescence (PL) spectrum of PANI-Ag nonocomposite is shown in Fig. 5. The emission wavelength is peaking at $439.60 \mathrm{~nm}$. This emission wavelength peak shifted towards to the blue when compared to the bulk PANI-Ag. This emission is due to the recombination of electron and hole pairs. This blue shift of PANI-Ag nanocomposite demonstrates the strong quantum confinement. The absorption wavelength was observed at $330.40 \mathrm{~nm}$ and the emission wavelength was observed at $439.60 \mathrm{~nm}$. The difference between the absorption and emission peak wavelength is $109.20 \mathrm{~nm}$. This indicates the emission associated with the transition of electrons from trap state of conduction band (or valence band). The photoluminescence studies show that the emission peak shifted towards the blue when compared to that of bulk PANI-Ag.

Thermogram of PANI-Ag nanocomposites is shown in Fig. 6. The silver content in the composite can conveniently be determined as a residue in TGA. The thermogram also provides additional information about the composition of the oxidation products. There is a first decrease in mass below $104.38^{\circ} \mathrm{C}$, associated with sample humidity; a step starting at $140.63^{\circ} \mathrm{C}$ is connected with the 
sample deprotonation and loss of nitric acid. The presence of two components differing in decomposition temperature is observed in composite. The presence of silver is also well identified.

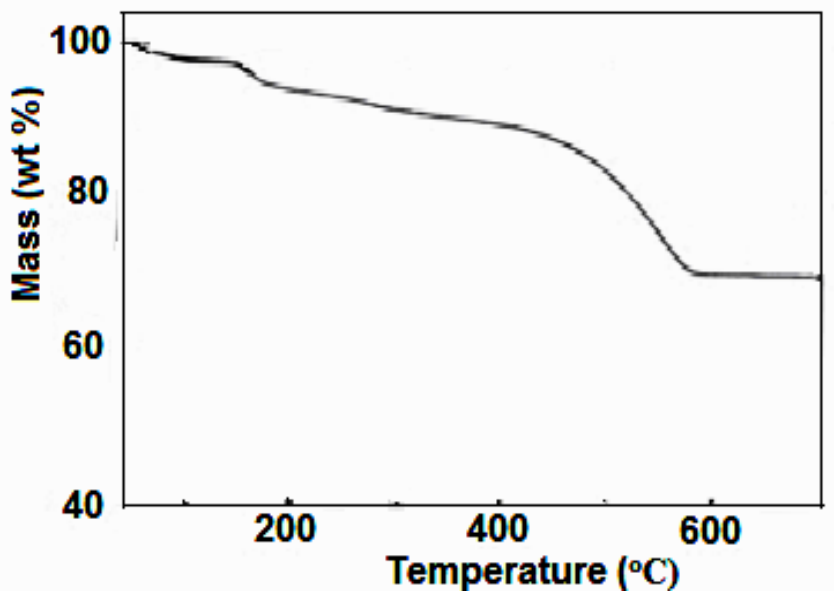

Fig. 6. Thermogram of PANI-Ag nanocomposites

Electrical conductivity of PANI-Ag nanocomposite is shown in Fig. 7. It is noted that the conductivity of the composites increases slowly with the increase of temperature until a temperature of around $70^{\circ} \mathrm{C}$ is reached, after which the conductivity decreases gradually. The increase in conductivity with temperature is a property of semiconductors. Such phenomenon has been reported for polyaniline and composites.

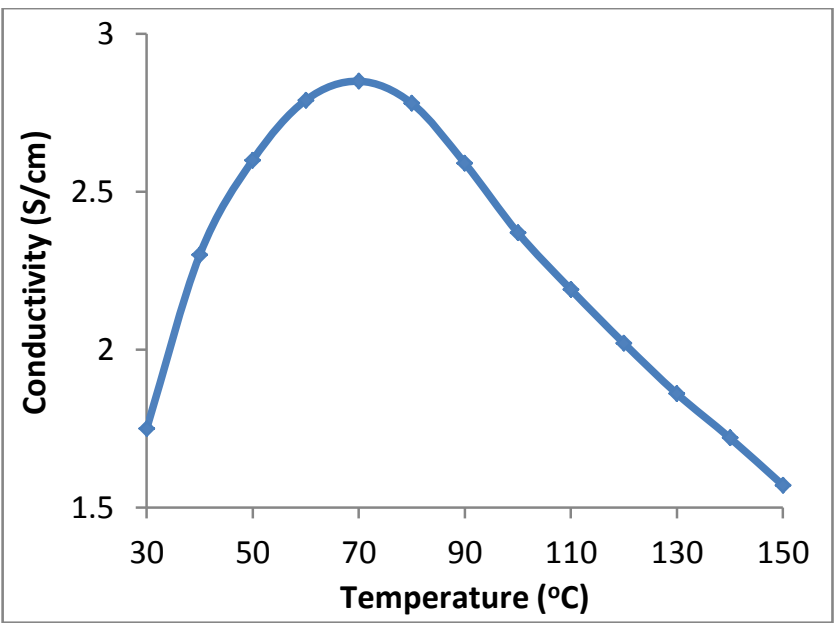

Fig. 7. Electrical Conductivity of PANI-Ag nanocomposite as a function of temperature.

The decreasing conductivity above $70^{\circ} \mathrm{C}$ could be due to the presence of absorbed water and its removal may have caused structural changes in the hygroscopic PANI polymer chains which revealed a small weight loss below $125^{\circ} \mathrm{C}$. The decreasing conductivity with increasing temperature is owing to chemical change, its degradation or evaporation of dopant. Furthermore, it has been reported that a dry sample has lower conductivity than a hydrated sample and loss of moisture results in a decrease of conductivity for polyaniline and PANI-Ag nanocomposite. Interfacial electronic interaction between polymer semiconductor and silver metal or the formation of electrical barriers can be the cause of these results. The increase of conductivity until the crictical point is attributed to polymer chain mobility and activation of dopant while the decrease of conductivity can be attributed to the volatization of dopant, follow by structural change. The change of chain structure by thermal treatment and interchange interaction between two components has an effect on morphological change. In addition, with increasing temperature, the intermolecular spacing between adjacent chains of the composites is decreased. The electric conductivity of composites represented by silver nanopaticles embedded in the matrix of a conducting polymer is expected to be high. The combination of PANI as a semiconducting polymer with silver as a noble metal may produce hybrid material that behaves as semiconductor at low temperature and as metal at high temperature.

\section{Conclusion}

PANI-Ag nanocomposite was successfully synthesized by simple wet chemical route by colloidal chemistry. PANIAg nanocomposite exhibits the significant blue shift. PANI-Ag nanocomposite is well crystalline with average crystallite size of $12 \mathrm{~nm}$. SEM study reveals the rod structure surface morphology of PANI-Ag nanocomposite. The combination of PANI as a semiconducting polymer with silver as a noble metal may produce hybrid material that behaves as semiconductor at low temperature and as metal at high temperature.

\section{Acknowledgement}

The authors gratefully acknowledge UGC, New Delhi (India) for financial assistance provided to carry out this work through major research project (F 39-540/2010 (SR)).

\section{Reference}

1. Zhang, Q.; Liu, F.; Li, L.; Pan, G.; Shang, S. J. Nanopart. Res. 2011, 13(1), 415 .

DOI: $10.1007 / \mathrm{s} 11051-010-0070-8$.

2. Bal, S.; Samal, S.S. Bull. Mater. Sci. 2007, 30 (4), 379. URL:http://hdl.handle.net/2080/497

3. MacDiarmid, A.G. Curr. Appl. Phys. 2001, 1, 269. DOI: $10.1016 / \mathrm{S} 1567-1739(01) 00051-7$

4. Roth, S.; Groupner, W. Synth. Met. 1993, 57(1), 3623 DOI: $\underline{10.1016 / 0379-6779(93) 90487-\mathrm{H}}$

5. Sezer, A.; Gurudas, U.; Collins, B.; Mckinlay, A.; Bubb, D.M. Chem. Phys. Lett. 2009, 477, 164. DOI: $10.1016 /$ j.cplett.2009.06.070

6. Crespilho, F.N.; Lost, R.M.; Travain, S.A.; Oliveira, O.N.; Biosens, Z.V.; Bioelectron. 2009, 24, 3073.

DOI: $10.1016 / j . b i o s .2009 .03 .026$

7. Chowdhury, A. Sensors Actuat. B. 2009, 138, 318. DOI:10.1016/j.snb.2009.01.019

8. Wang, W.Q.; Zhang, R.F. Synth. Met. 2009, 159, 1332. DOI: $10.1016 /$ j.synthmet.2009.03.002

9. Wang, W.Q.; Shi, G.Q.; Zhang, R.F.; J. Mater. Sci. 2009, 44, 3002. DOI: $10.1007 / \mathrm{s} 10853-009-3416-9$

10. Li, W.G.; Jia, Q.X.; Wang, H.L. Polymer 2006, 47, 23. DOI:10.1016/j.polymer.2005.11.032

11. Sedenkova, I.; Trchova, M.; Stejskal, J.; Prokes, J.; ACS Appl. Mater. Interf. 2009, 1, 1906

12. Bouazza, S.; Alonzo, V.; Hauchard, D. Synth. Met. 2009, 159, 1612. DOI: 10.1016/j.synthmet.2009.04.025

13. Blinova, N.V.; Stejskal, J.; Trchova, M.; Sapurina, I.; CiricMarjanovic, G. Polymer 2009, 50, 50. 
DOI:10.1016/j.polymer.2008.10.040

14. Blinova, N.V.; Bober, P.; Hromadkova, J.; Trchova, M.; Stejskal, J.;

Prokes, J.; Polym. Int. 2010, 59(4), 437.

DOI: $10.1002 / \mathrm{pi} .2718$

15. Li, X.; Gao, Y.; Gong, J.; Zhang, L.; Qu, L.Y. J. Phys. Chem. C 2009, 113,69 . DOI: $10.1021 / \mathrm{jp} 807535 \mathrm{v}$

16. Beck, R.D.; St. John, P.; Whetten, R.L. Science. 1991, 253, 879. DOI: $\underline{10.1126 / \text { science. } 253.5022 .879}$

\section{Advanced Materials Letters}

\section{Publish your article in this journal}

ADVANCED MATERIALS Letters is an international journal published quarterly. The journal is intended to provide top-quality peer-reviewed research papers in the fascinating field of materials science particularly in the area of structure, synthesis and processing, characterization, advanced-state properties, and applications of materials. All articles are indexed on various databases including $\mathrm{DOAJ}$ and are available for download for free. The manuscript management system is completely electronic and has fast and fair peer-review process. The journal includes review articles, research articles, notes, letter to editor and short communications. 